\title{
Robotics Feasibility in the Construction Industry
}

\section{By: Roozbeh Kangari}

\section{INTRODUCTION}

At the present time, robotics in construction industry is in the early stage of research. Before robots can practically be implemented in the industry, major problems such as: how construction processes can be automated; what are the sequential stages in construction automation; and what level of automation is feasible for a given construction operation should be investigated. Unlike the manufacturing industry, a construction site is a dynamic and random environment, therefore, a fully automated process requires a very intelligent control system, sophisticated sensors for feedback, an efficient material-handling system, and an advance mobility system. Under these conditions, it has become useful to explore at least those problems in the range of preliminary steps for the robotics feasibility in the construction industry.

Robot is used extensively by the manufacturing industry. However, construction industry has unique characteristics which makes the robotization in most cases not a feasible alternative at the present time. It is not expected that robots enter the construction trades before the end of next decade. The construction site is a random environment requiring a robot of highly sophisticated intelligence combined with a large load range and need for mobility. It seems that in the early days of robotics application in construction industry, the awareness of construction site hazards to labors will provide the prime motivation to design and use a robot that would perform the tedious, repetitive, boring, dangerous and unpleasant construction jobs. 
Robot technology is not new, but many industries as construction are only just beginning to realize the impact that full automation could have in their production. Today, construction robots are still on the stage of research, and there are only few practical construction robots developed in the U.S., Japan, and some other countries. However, among all these robots only one or two may be called real construction robot, and the rest are partially automated construction equipment.

Although today there is differences of opinion about exactly what a construction robot is, but in general may be defined as a fully automated mechanical device that can be programmed to perform construction tasks. In other words, robots are the machines which are controlled by computers.

A further essential question is the determination of an economical and practical level of automation for construction processes. There should be an optimum level of automation for each type of construction operation since excessive application of automation to a given process may not be economical. In certain cases, partial automation or robotization may even lead to an increase in the unit price. One approach to this question is to develop sequential stages in automation and perform a feasibility analysis for each stage.

SEQUENTIAL STAGES IN AUTOMATION:

To define an optimum level of automation for a given construction operation, the following five basic classifications as shown in Fig. 1 are developed:

1) Pure manual labor construction operation which involves no tools, e.g., material handling by hand, or packing.

2) Manual labor construction operation with tools, e.g., manual 
1) Pure Manual Labor Construction Operation

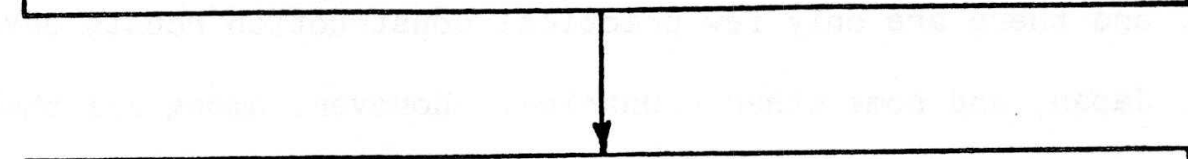

2) Manual Labor with Tool Construction Operation

3) Man-Machine Construction Operation (Conventional Construction Equipment)

4) Man-Machine-Computer Construction Operation (Partially Automated Construction Equipment)

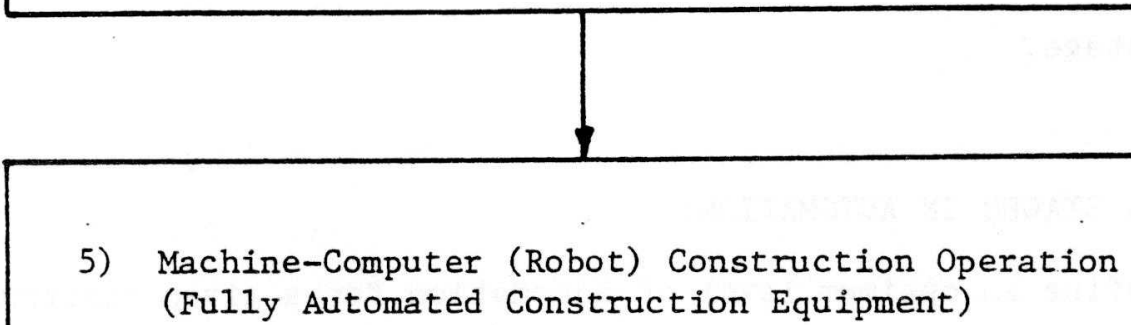

Fig. 1. - Sequential Stages in Construction Automation Process 
excavation with a shovel.

3) Conventional construction equipment, or man-machine operation. These are the construction machines which are controlled by human, e.g., drilling rock by a conventional drill, or excavation by a conventional loader. Most of the construction equipment at the present time are under this classification. Fig. 2 represents a simple graphical model of this stage.

4) Partially automated construction equipment, or man-machinecomputer operation. As shown in Fig. 3, this stage of automation improves the conventional construction equipment by adding a partially automated control system to the actuators, e.g., laser leveling grader, automatic gear shifting scrapers, hydraulic excavator with bucket tilt control, or remote control construction equipment for the construction work in dangerous places.

5) Fully automated construction equipment (robot), or machinecomputer operation, e.g., SSR-2 spray robot for fireproof spraying on steel structures, developed by the Research Institute and Construction Machinery Division of Shimizue Construction Co. in Japan. In the U.S., the Civil Engineering and Construction Robotics Laboratory at Carnegie-Mellon University is heavily involved in research and development of the construction robots to perform tasks in environment that are unsafe for human. These robots require occasional human involvement as shown in Fig. 4.

How does a robot operate? Essentially the computer of robot is provided with information representing a model of the robot, with details of the environment, data relating to the tasks to be performed and with a number of planning algorithms. When in operation it receives at all times 


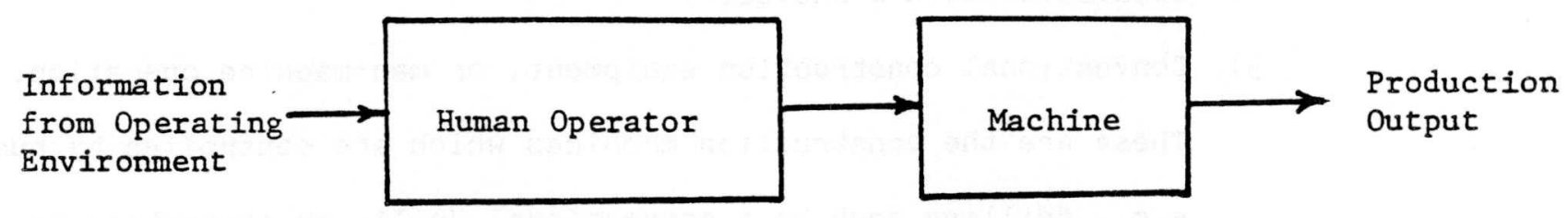

Fig. 2. - Conventional Construction Equipment

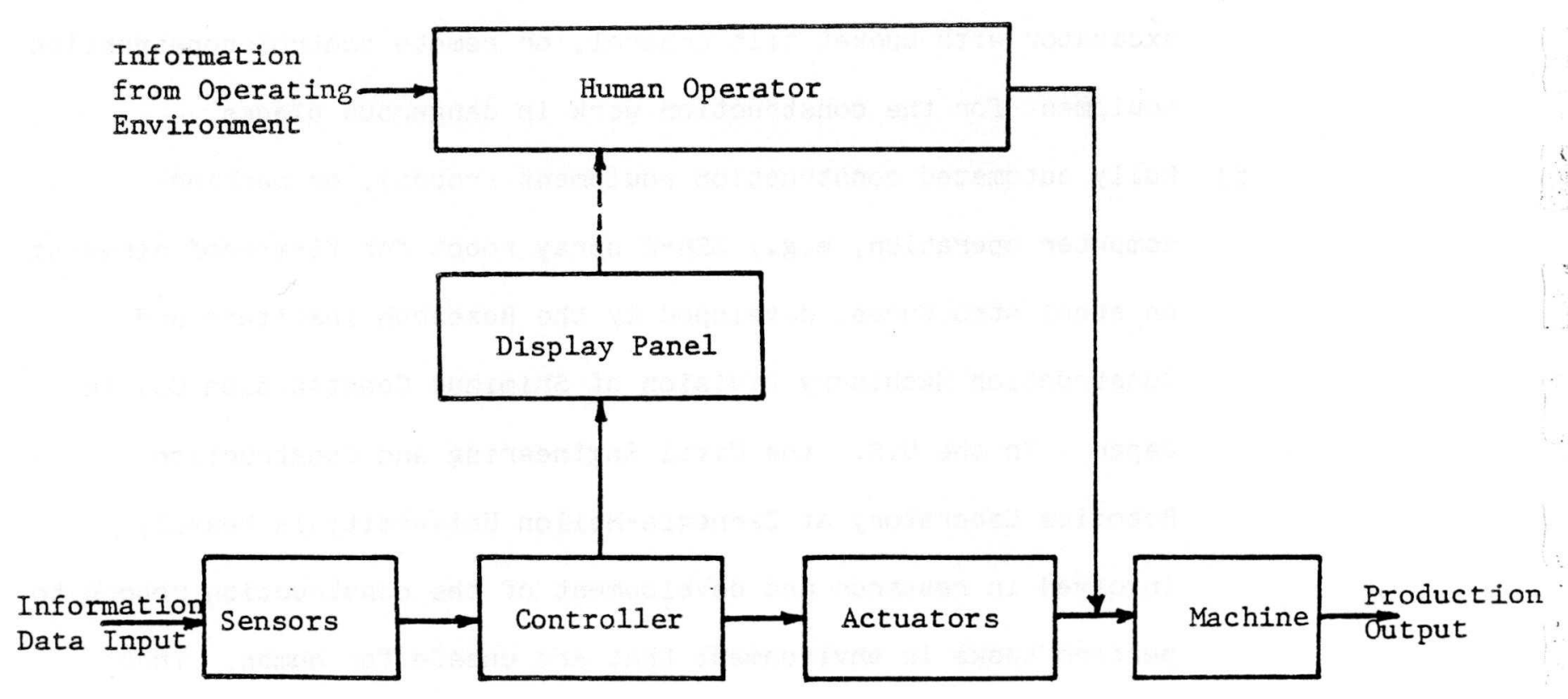

Fig. 3. - Partially Automated Construction Equipment 


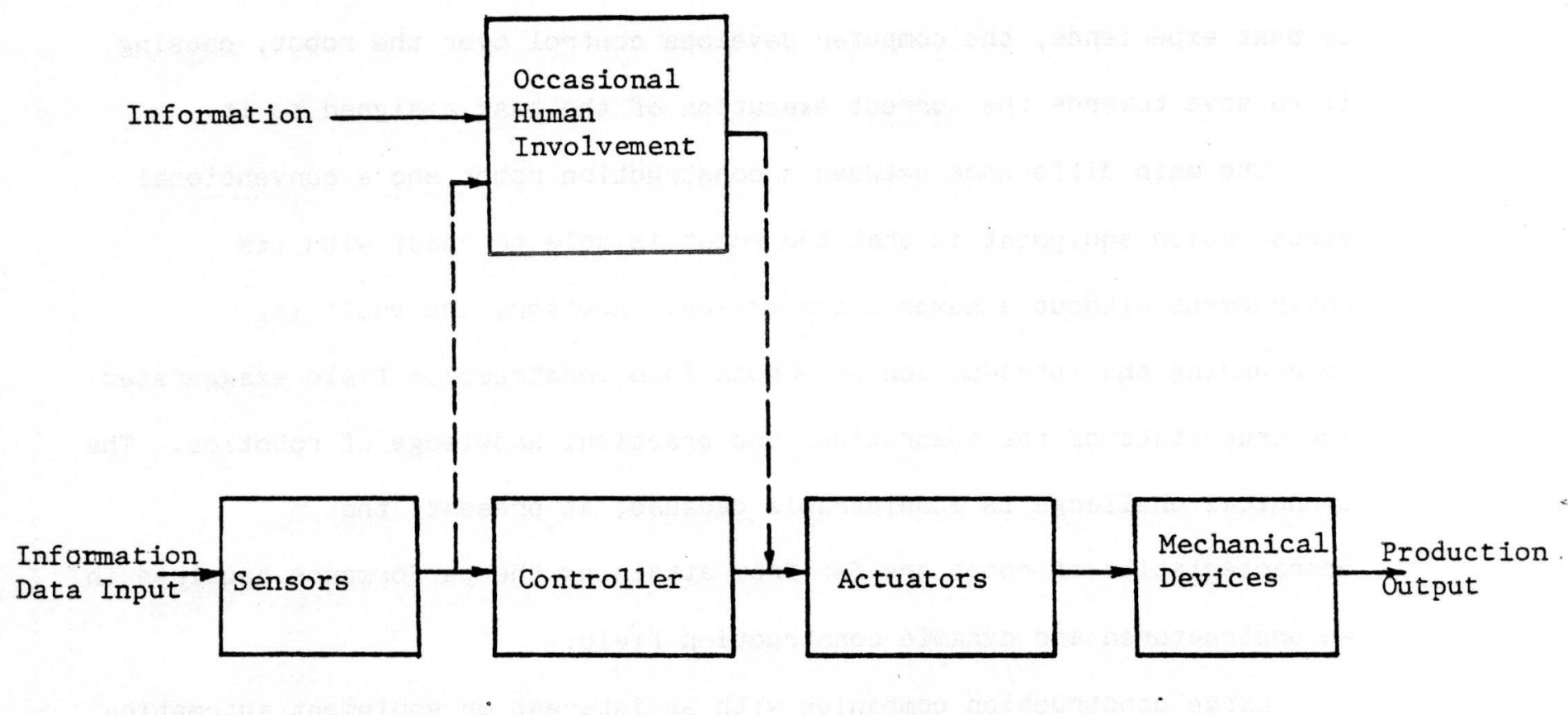

Fig. 4. - Fully Automated Construction Equipment (Robot) 
information concerning the robot with internally sensed information, and the environment with externally sensed information. By using this information in conjunction with planning algorithms, which can refer back to past experience, the computer develops control over the robot, causing it to move towards the correct execution of the task assigned to it.

The main difference between a construction robot and a conventional construction equipment is that the robot is able to react with its environment without a human intervention. However, the publicity surrounding the introduction of robots into construction field exaggerates the true state of the theoretical and practical knowledge of robotics. The technical challenge is considerable because, at present, the characteristics of robot are far from attaining the performance required in an unstructured and dynamic construction field.

Large construction companies with an interest on equipment automation have not given a great deal of attention to research in robotics. There are only a few international contractors who have introduced robotics into their field, however, these robots are not capable of detecting the complex information directed to them from the environment.

If the number of repetitive operations are very large and the output product is fixed, then it might be economical to implement a fixed automation plant. For example, if a prefabricated plant is planning to build a large (infinite) number of fixed construction products (e.g., prestressed concrete beams) which does not require any change in size or type of material, then a fixed automation may reach a lower unit price than a flexible automated plant. This is due to the large volume of production and a lower variable cost. 
Considering these sequential stages, the objective of this paper is to describe the feasibility of the last stage (robotization) in relation with the other stages. In other words, what construction operations should be robotized. 
II. FEASIBILITY ANALYSIS

A modelling procedure is needed to evaluate the feasibility of developing robotics and justifying the implementation of robotics for certain construction operations. Two feasibility models using seven basic variables are proposed. The ultimate output of the models indicate whether the robotization is appropriate for a particular construction operation or not. In reality, robotics feasibility and justification is interdisciplinary since it involves the input of several professional groups, therefore, this paper can only provide a guide for evaluation and discuss general considerations.

The goal is to develop generalized mathematical models for evaluating the suitability of robotics applications in the construction industry. That is, what construction operations can be robotized? To answer this question, a robotization index, I, must be obtained such that a given value or range of values indicates whether robotics is feasible for a particular construction operation at a given point in time. A linear scale of the index can be utilized as shown in Fig. 5 .

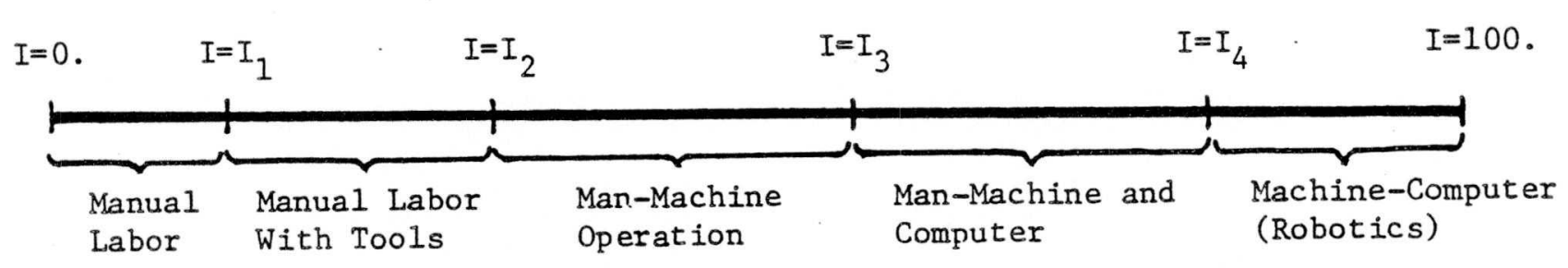

Fig. 5. - Linear Scale of Construction Operation Index 
To determine this index, the following seven major variables affecting on the feasibility of the robotics are considered:

1) Cost Effectiveness and Economical Analysis

2) Level of Hazardous

3) Productivity

4) Quality Improvement

5) Standardization of Design and Level of Repetitiveness

6) Union Resistance

7) Technologically Feasible

Any construction operation, if desired to be robotized, should satisfy a certain level of these variables. Since each construction operation is unique in nature, therefore, each operation will have different weight factors to the above variables.depending on their level of importance in the operation. For example, in a welding operation inside a nuclear power plant with a high level of radiation, variables 2 and 7 will have higher weights than variable 5 .

These variables must be analyzed in order to determine whether a particular operation should or should not be robotized. Next, these variables are defined and discussed.

\section{Cost Effectiveness and Economic Analysis:}

Applying robotics to a particular construction operation will most likely involve a large initial capital investment. Capital investments are based on the evaluation of the spending requirements and the returns 
generated over the lifetime of the equipment. Sometimes a particular construction operation is technologically feasible but not financially.

To determine whether a robot is economically feasible, costs and benefits should carefully be studied. There are basically two major economic analysis techniques for evaluating the desirability of a robot: 1) payback period analysis; and 2) cash flow analysis.

The payback period estimates the length of time (e.g., how many years) it will take to recover investment costs as shown in Eq. 1.

$$
\text { Payback Period }=\frac{\text { Total Initial Capital Investment }}{\text { Annual Savings Resulting from the Robot }}
$$

In general, a determination of the total investment required is necessary, then the effect of the investment on operation's expenses and profitability should be analyzed. Eq. 2 provides a simplified way to determine a payback period:

$$
P=\frac{C}{L+D+I-M}
$$

in which $P=$ payback period in years; $C=$ total initial capital investment required in robot and accessories, $L=$ savings on annual labor costs due to the replacement of the robot; $D=$ annual depreciation; $I=$ annual savings resulting from increase in annual production and improved product quality, the value of I should be considered negative. if there is a decrease in annual production; and $M=$ annual robot maintenance costs. In general, the values of $L$ and $I$ can be estimated from Eqs. 3 and 4, as follow:

$$
\begin{aligned}
& L=W-S \\
& I=q(L+Z)
\end{aligned}
$$

in which $W=$ annual cost of workers before the implementation of robot; $S=$ annual cost of staffing after the use of robot, $q=$ speedup (or slowdown) 
factor due to the increase (or decrease) of annual production when a robot is used; and $Z=$ annualized value of the robot, in general, it might be assumed as annual depreciation. Current robots have payback periods of $2-3$ years when compared against direct labor.

Another method of economic analysis is the cash flow analysis. In this case, either annual rate of return (internal rate of return) on robot investment can be estimated, or the net present value of the investment can be calculated by applying a required or an appropriate rate of return for the robot. This method requires that an expected net cash flow be developed, and a discount rate must be assumed. Table 1 identifies the major cost and benefit items to be considered in the cash flow analysis.

\section{Level of Hazardous}

.Hazardous construction operations are very suitable for the robotization. The distinction between unsafe operations and hazardous operations should be made. Unsafe operations are assumed those in which there is a high occurrence of worker accidents. Accidents are considered to be the fault of the worker, either through carelessness or by the misuse of equipment. Hazardous operations are assumed those operations which expose the worker to an unhealthy environment (e.g., dust, radiation, heat, etc.). The worker is not considered responsible for the conditions but due to the nature of the operation, unhealthy human exposure is required. Historical data generally indicates the frequency of job related accidents, while standards relating to hazardous operations are provided by OSHA.

Some of the construction operations are hazardous, therefore, governmental and private agencies have dedicated special attention to this kind of operations. Several studies have conducted in which permissible 
TABLE 1. - Economic Analysis of a Robot

\begin{tabular}{|c|c|c|c|}
\hline \multicolumn{2}{|c|}{ Cash Flow } & \multicolumn{2}{|r|}{ Items to be Considered } \\
\hline & $\begin{array}{l}\text { CASH } \\
\text { OUT } \\
\text { FLOWS }\end{array}$ & $\begin{array}{l}\text { a) } \\
\text { b) } \\
\text { c) } \\
\text { d) }\end{array}$ & $\begin{array}{l}\text { Total Robot Cost: } \\
\text { Robot } \\
\text { Accessories } \\
\text { Options } \\
\text { Installation } \\
\text { Maintenance Cost: } \\
\text { Spare Parts } \\
\text { Maintenance } \\
\text { Downtime Cost } \\
\text { Increase in Energy Cost }\end{array}$ \\
\hline & $\begin{array}{l}\text { CASH } \\
\text { IN } \\
\text { FLOWS }\end{array}$ & $\begin{array}{l}\text { a) } \\
\text { b) } \\
\text { c) } \\
\text { d) }\end{array}$ & $\begin{array}{l}\text { Savings on Labor Costs } \\
\text { Productivity and Quality Improvement } \\
\text { Depreciation Saving Through Tax } \\
\text { Salvage Value }\end{array}$ \\
\hline
\end{tabular}


exposure limits for a variety of noxious elements commonly found in construction operations have been set. In determining if a particular operation is hazardous, the following elements should be analyzed.:

1) Concentration of Dust. Asbestos Zinc

Berylium Cement

Uranium Fibrous Glass

2) Temperature Levels

3) Air and Water Pressures

4) Noise

5) Radiation

Some of the current permissible exposure levels that have been set by different governmental and private agencies are:

Dust - Any job site in which atmosphere contains dust particles smaller than 5 um in aerodynamic diameter are considered hazardous for the human lungs.

Toxic Dust, Gases, and Fumes.

- Job sites in which Chemical particles and substances are found in a level superior to $.15 \mathrm{mg} / \mathrm{m}^{3}$ of air.

Noise - Any job site in which sound levels exceeds $115 \mathrm{dBA}$. is considered hazardous for the human health.

Radiation.

- The permissible exposure levels should be $\leq 3$ REM. per calendar quarter or $\leq 5$ REM. per year.

Unsafe operations such as: sloped excavations, tunnel excavations; and scaffolding operations can also be analyzed in similar way. 


\section{$\underline{\text { Productivity }}$}

Productivity levels in a particular operation are indicators of the effectiveness of the different resources involved in the operation.

In order to determine if a particular operation is suitable for robotization from the point of view of productivity, it is necessary to set a desired or expected productivity level. After having conducted a detailed and precise study of the productivity variation according to the type of machine being utilized and according to the expected robot productivity variation, the decision-maker should be in the position to decide if the operation is suitable for robotization or not.

Generally, productivity of an operation is measured by dividing the total number of units produced by the total amount of resources utilized in a determined period of time.

Productivity can simply be defined as the ratio of output to input, typically given as units produced per man-hours required. A comparison between productivities of the current system and the proposed robotic system should be made. If historical data on productivity is not available then a study to determine these values must be made. Cyclone modelling of the operation's tasks and sub-tasks for both systems may be used to determine the value of productivity. Several assumptions may be needed to model the robotic system, especially if it is a new or unique application. The most desirable results would indicate that the robotic system provides greater productivity in the comparison.

If a construction operation is automated or robotized, it is expected to have a sharp increase in the productivity. The increased productivity, supposedly, gradually absorbs the cost incurred in the robot or automated equipment implementation. Obviously, productivity is not the only factor 
that pays for the robot. In some situations, the productivity achieved by a robotized operation remains the same, but substantial savings are expected to occur in other cost categories such as labor, overhead, etc., or even cost savings achieved by a better quality of the work.

A robot might have another uses in other projects. Therefore, the analysis must consider these possibilities, just to study whether or not the robot cost is commensurated by the better productivity achieved.

One must remember that certain construction operations involve a lot of risk. In this situation, the productivity plays a secondary role, because the main objective is to avoid detrimental and hazardous conditions. For these reasons, the project planner must weigh every factor accordingly to the desired goals.

\section{Quality Improvement}

One major reason for the implementation of robot is to produce a better quality compared to traditional systems. The results of quality analysis of the SSR-2 spray robot for fireproof cover work shows that the dispersion of the sprayed thickness decreased. Quality of a construction product can be measured by a numerical model which considers such characteristics as strength, dimension, color, and etc. Only the relevant characteristics of an operation product should be considered. There is a direct correlation between cost and the level of quality improved.

Standardization of Design and Level of Repetitiveness

The cyclic and repetitive operations are the most suitable operations to be robotized or automated. A repetitive routine operation is a 
that pays for the robot. In some situations, the productivity achieved by a robotized operation remains the same, but substantial savings are expected to occur in other cost categories such as labor, overhead, etc., or even cost savings achieved by a better quality of the work.

A robot might have another uses in other projects. Therefore, the analysis must consider these possibilities, just to study whether or not the robot cost is commensurated by the better productivity achieved. One must remember that certain construction operations involve a lot of risk. In this situation, the productivity plays a secondary role, because the main objective is to avoid detrimental and hazardous conditions. For these reasons, the project planner must weigh every factor accordingly to the desired goals.

\section{Quality Improvement}

One major reason for the implementation of robot is to produce a better quality compared to traditional systems. The results of quality analysis of the SSR-2 spray robot for fireproof cover work shows that the dispersion of the sprayed thickness decreased. Quality of a construction product can be measured by a numerical model which considers such characteristics as strength, dimension, color, and etc. Only the relevant characteristics of an operation product should be considered. There is a direct correlation between cost and the level of quality improved.

\section{Standardization of Design and Level of Repetitiveness}

The cyclic and repetitive operations are the most suitable operations to be robotized or automated. A repetitive routine operation is a 
desirable operation characteristic for the robotization. A construction operation should be broken down into individual processes, tasks, and subtasks. The amount and type of repetition in each of these work divisions should be analyzed. The decision-maker determines the number of cyclic motions required in the production of one unit.

Standardization of design also involves repetition but on a larger scale. Here, repetition is studied on the project or activity level. Basically, this parameter evaluates the number of production units required for successful robot implementation. Justification depends upon whether the number of production units fall within an optimum range. If not, perhaps some other man/machine system is more appropriate.

There are several means by which the number of production unit in a project may be modified to fall within the optimum range for robotization. In the project planning phases it is advantageous to orient various building components (i.e. steel framing, doors, windows, rooms, etc.) in a regular and predictable manner increasing the feasibility of robotization by increasing the quantity of repetitious work cycles. Standard dimensions, regular geometric shapes and standard size fixtures would simplify implementation. Simplifying the construction design would in turn simplify the robot's job, reduce the necessary 'learning period' (teaching and reprogramming) and thereby increase robot effectiveness.

Standard design and repetitive operation are two factors that are required for robotization or automation of any construction operation. Several construction projects involve a determined amount of repetitive operations but it does not mean that this operation should be immediately robotized. Basically, the decision is based on quantity 


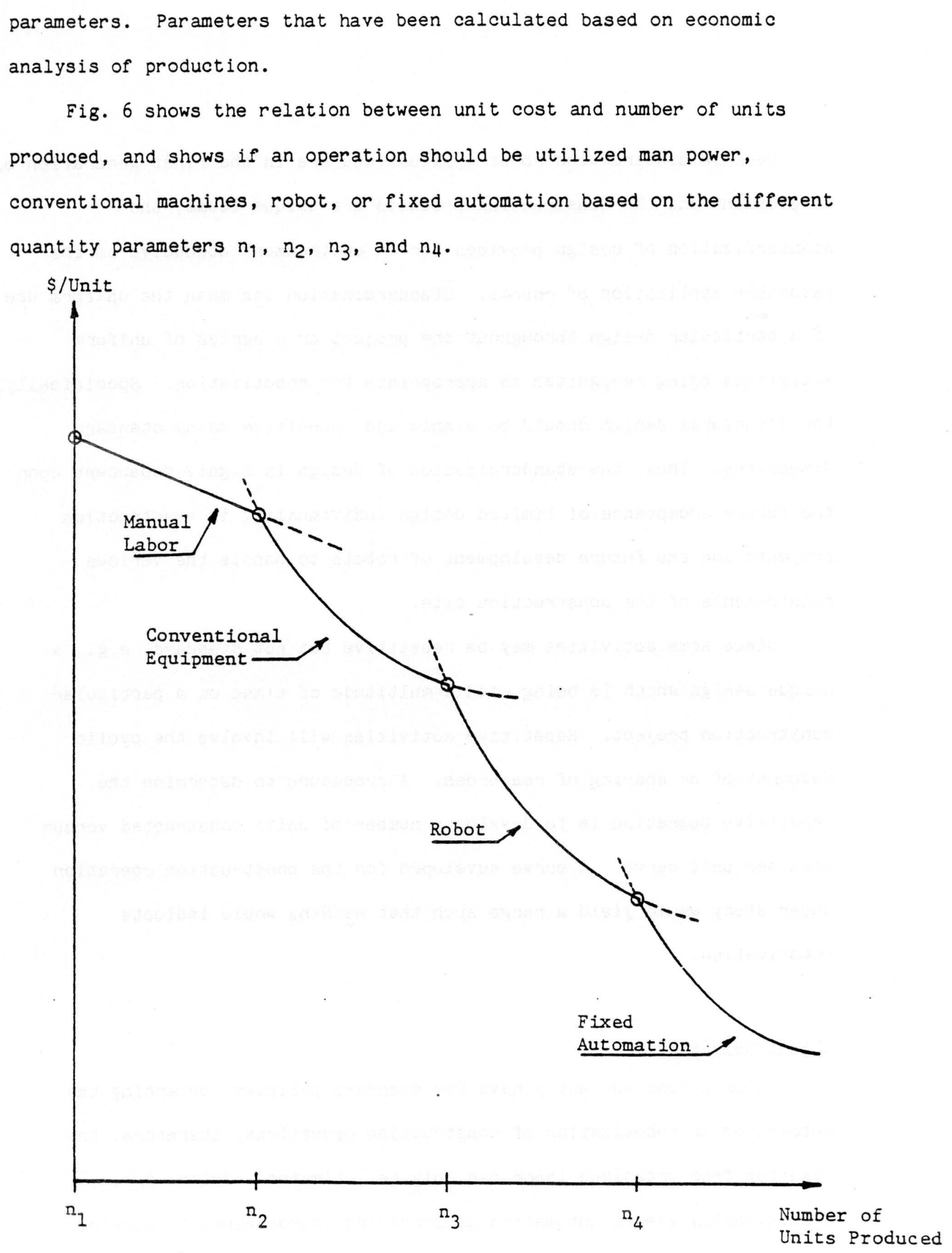

Fig. 6. - Economic Stages of Automation vs. Level of Repetitiveness 
Because construction robot applications are in the first generation of development and the construction products are unique items, the standardization of design provides for an environment conducive to the favorable application of robots. Standardization can mean the uniform use of a particular design throughout the project or a series of uniform activities being recognized as appropriate for robotization. Specifically, the structural design should be simple and repetitive using standard dimensions. Thus, the standardization of design is highly dependent upon the future acceptance of limited design individuality in construction projects and the future development of robots to handle the various requirements of the construction site.

Since some activities may be repetitive but not standard, e.g., a unique design which is being used a multitude of times on a particular construction project. Repetitive activities will involve the cyclic movement of or sharing of resources. A procedure to determine the repetitive operation is to develop a number of units constructed versus cost per unit curve. A curve developed for the construction operation under study would yield a range such that $n_{3}<N<n_{4}$ would indicate robotization.

\section{Union Resistance:}

Labor unions currently have few standard policies concerning the automation or robotization of construction operations, therefore, the reaction from organized labor can only be estimated. Unions have traditionally viewed automation as providing improvements to working conditions and in most cases respond in a positive manner. 
Union resistance is considered to be somewhat dependent upon the following:

- number of workers being displaced

- union strength in the area

- policies of management (advance notice to union officials, placement programs for displaced workers, etc.)

This parameter is more difficult to model because no definite measurement scale of union resistance exists.

Generally, unions resistance vary depending upon the kind of operation under consideration. If the robotization of a particular operation will represent the possibility of a massive labor's displacement, unions resistance could be so drastic that it could determine the success of the whole operation.

In order to minimize unions resistance, the decision-maker should be aware of the social implications of introducing new technology in the operation. Obviously, solutions to the problem could be possible, such as relocation of displaced workers within the industry or in other industries.

To reduce the union resistance, the following major factors must be considered by the contractors:

1. minimum social disruption should be generated

2. job safety and worker satisfaction should be given large consideration

3. the overall quality of life for workers should be enhanced. An interview was conducted with the Business Manager of the Local 438 of the Laborers International Union of North America, located in Atlanta, Georgia, which is affiliated with the AFL-CIO. The objective was to ascertain the construction laborer's union's understanding of robotization 
in the construction industry and the policy with regards to the robotization. The following questions ( $Q$ ), and responses ( $R$ ) were resulted from the interview:

Q-1 What is your idea of a robot?

R-1 A machine that accomplishes a task in a methodical and precise way. Not the science fiction version of humanoid-like machines in the movie Star Wars

Q-2 Do you see a place for robotics in the construction industry?

R-2 Yes, such as in painting applications, but we will still need human directions and involvement in site safety considerations.

Q-3 Are you familiar with the progress made in other countries such as Japan towards robotization of the construction industry?

R-3 I have heard bits and pieces about foreign robotics development but have no actual hands-on experience with foreign robot advancement in construction.

Q-4 Does the union have any input with regard to non-union jobs?

R-4 None whatsoever, and union influence is weak in Atlanta and is decreasing throughout the country.

Q-5 Does the union have a policy with regard to robots in construction? If not, is there any policy on automated equipment?

R-5 There is no current policy on robots with regards to construction. The policy with regards to any labor saving device is not to hinder any increase in productivity. However, any unique items are always negotiable points in contracts between the union and the construction contractor.

Q-6 Would the union object to placing robots in hazardous and/or harmful construction tasks? 
R-6 No, but it would be a negotiable item requiring assurances that the task be accomplished properly. I don't believe any construction job can be handled without human assistance. (This goes beyond supervision into actual task accomplishment.)

Q-7 Is the current and future work environment in construction large enough to absorb a small percentage of workers who could be displaced by robots? If so, what percent would the union feel comfortable with?

R-7 Take two of the same construction jobs over the last 30 years. A job using 150 bricklayers in 1950 would use 40 or so today because of improved construction techniques, materials, etc. There is no place to absorb workers displaced by robots. At this time, no percentage of displacement is a comfortable prospect.

Q-8 If robots become a reality in the construction field, what in your opinion will be the most significant changes brought about in the workplace? To the individual worker?

R-8 As many workers would be needed to direct or maintain the robots as are now needed to accomplish the work. Look at computers, which equate to robots in the sense of mechanizing human work tasks. They have created as many jobs as they have eliminated. (It was pointed out that the new jobs created were different and required a retraining process.)

Q-9 If robots become feasible, would the economics of dollar savings be enough justification to displace workers? If not, what is the union's flexibility on this issue?

R-9 The union has never stood in the way of progress. The papers 
have given the unions bad press. In the last 30 years the displacement of workers has continually increased, and the union has accepted this as part of progress. The union has never struck against improvements.

Q-10 What stipulations would the union demand so that the least amount of disruption would affect the worker displaced by robotization?

R-10 Retraining the displaced workers so that they could maintain their self-respect and lead productive lives. This is the basic concept we would negotiate for.

Q-11 Do you believe that a future situation can exist where humans and robots work in the same environment without conflict?

R-11 Yes, robots can be utilized in construction working side-byside with humans. It is happening now in automobile factories.

Q-12 Since the introduction of automation did not cause a mass unemployment crisis, do you see a parallel occurrence with the introduction of robots?

R-12 During my lifetime, there have been many revolutionary changes and mass unemployment did not result unless a depression was occurring. Robots, automation, whatever will not cause mass unemployment as long as people are retrained.

Q-13 Do you foresee a larger impact on minorities such as women and blacks from the robotization of the construction site?

R-13 No, not in union represented work. The union is an equalizer. Job assignments are handled fairly on a first-come-first-serve basis.

Q-14 An extreme reaction to robotics could be construction site sabotage. Could you foresee such incidents even if the unions 


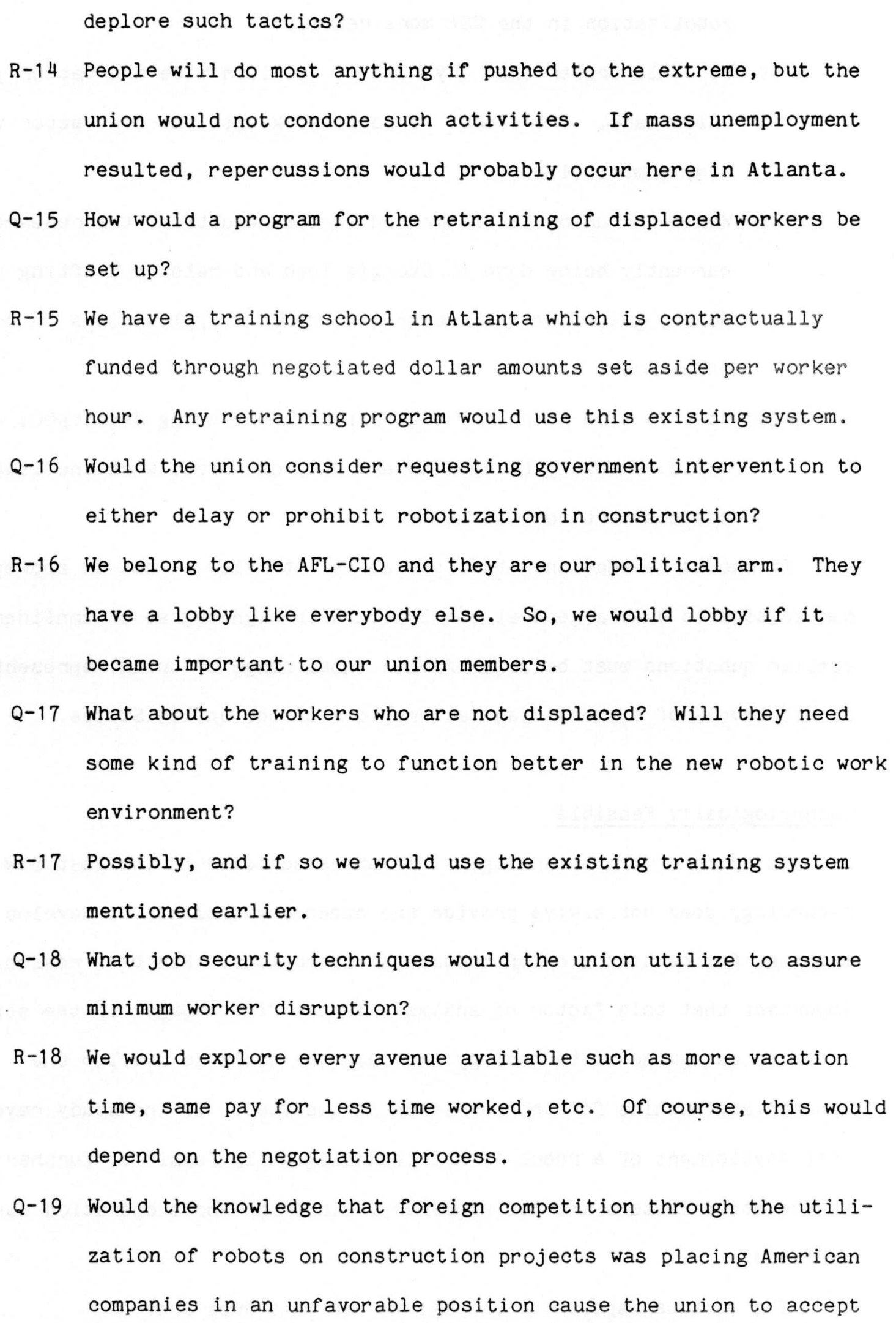


deplore such tactics?

R-14 People will do most anything if pushed to the extreme, but the union would not condone such activities. If mass unemployment resulted, repercussions would probably occur here in Atlanta.

Q-15 How would a program for the retraining of displaced workers be set up?

R-15 We have a training school in Atlanta which is contractually funded through negotiated dollar amounts set aside per worker hour. Any retraining program would use this existing system.

Q-16 Would the union consider requesting government intervention to either delay or prohibit robotization in construction?

R-16 We belong to the AFL-CIO and they are our political arm. They have a lobby like everybody else. So, we would lobby if it became important to our union members.

Q-17 What about the workers who are not displaced? Will they need some kind of training to function better in the new robotic work environment?

R-17 Possibly, and if so we would use the existing training system mentioned earlier.

Q-18 What job security techniques would the union utilize to assure minimum worker disruption?

$\mathrm{R}-18$ We would explore every avenue available such as more vacation time, same pay for less time worked, etc. Of course, this would depend on the negotiation process.

Q-19 Would the knowledge that foreign competition through the utilization of robots on construction projects was placing American companies in an unfavorable position cause the union to accept 


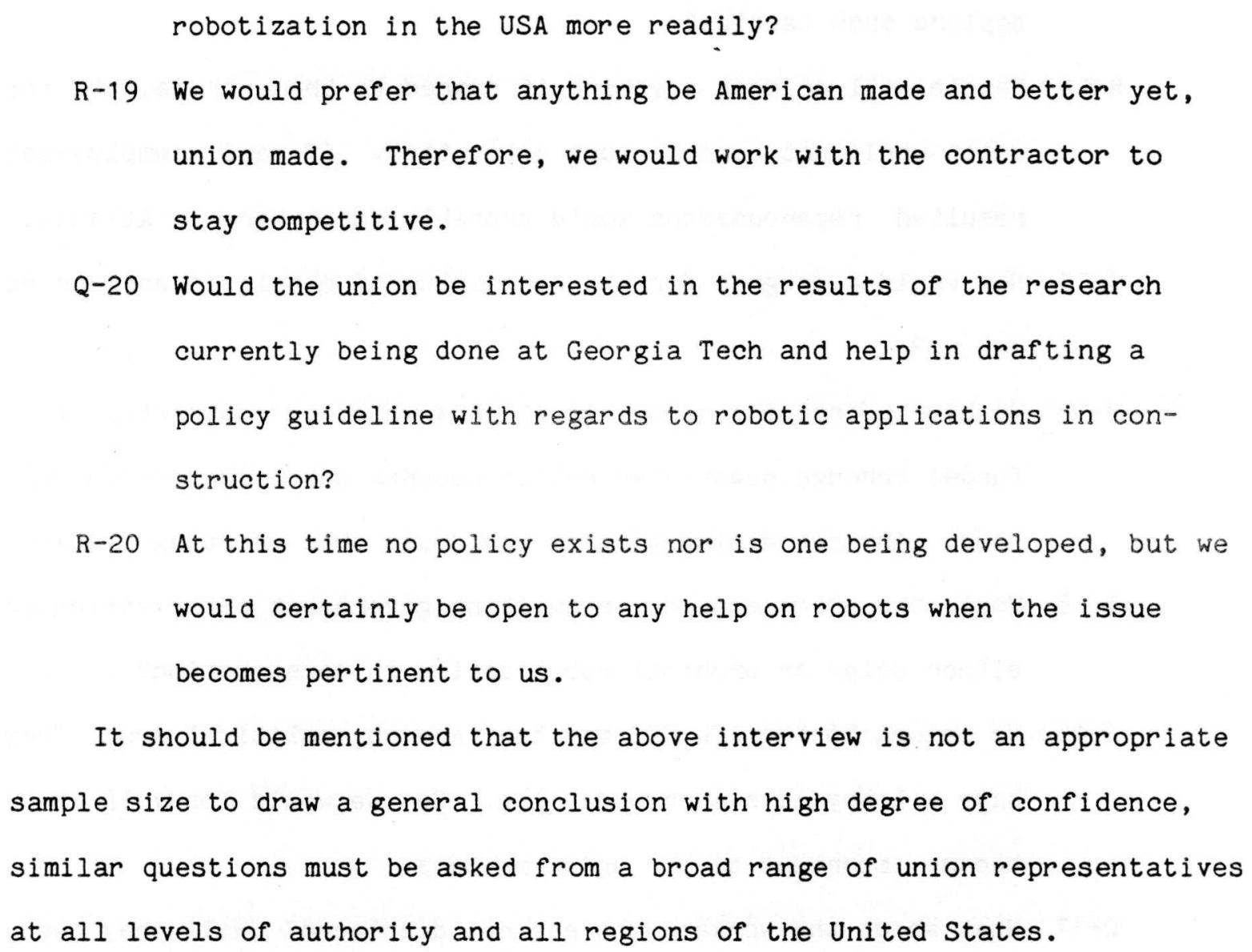

\section{Technologically Feasible}

In spite of the technological advances achieved in the last few years, technology does not always provide the necessary elements to develop machines for certain kind of industrial operations. For this reason, it is important that this factor be analyzed in the first stages of the study in order to determine if technology provides the tools to develop the appropriate machine for the operation in question. If the study reveals that development of a robot is not technologically feasible, further study of the other factors are not necessary, since the whole operation cannot be achieved.

The various aspects to be analyzed in this area are: 
1) Type of Mobility of Robot

a. Wheels, tracks or walking devices

b. Carrieage system (traveling and standing frames)

2) Robot's Manipulators

3) Control Systems

4) Methods of the Construction Material Supply

5) Weight of Robot (within design load)

6) Size of Robot

7) Robot's Safety Functions (human life and limb protection)

It is expected that mobile robots will find increased popularity in construction industry. A fixed robot has a limited sphere of operation and is not appropriate for the construction sites.

A construction wheeled vehicle robot, such as a motor car, with firmly inflated tires represents an ideal system with minimum eneregy to operate on smooth surfaces which have sufficient friction to the wheels to propel and steer the robot without slipping. Wheeled systems can only operate over relatively smooth surfaces. The track systems are the known alternatives to wheels for rough ground mobility. 


\section{FEASIBLITY MODELS}

Two basic feasibility models are presented for justifying the implementation of robotics in certain construction operations: 1) a simplified management decision model; and 2) utility decision model. The first step in the formation of the models is to identify the relevant variables. The second step is to develop a criteria for estimating a management decision index.

\section{1) Simplified Management Decision Model:}

This model allows the management to make a quick decision about the automation or robotization of a particular construction operation. The seven major variables discussed previously are considered as major management decision variables as shown in Table 2. Different weight factors should be assigned by the management to each variable. These weight factors indicate the level of importance of the variables, and they may vary one operation to the other. Columns 3 and 4 show the actual and acceptable standard levels of the variables. For example, as shown in Table 2, for a given construction operation the level of dust is measured as $3 \mu \mathrm{m}$, however based on the N.S.C. safety and health standards, the acceptable level of dust is $5 \mu \mathrm{m}$. Since the measured particles of dust are smaller than the standard size, therefore, this construction operation is unsafe, and it is appropriate for the robotization.

The index for other variables are evaluated as described in previous sections. Some indices may not be possible to evaluate, such as union resistance, in this case, a 'Yes' or 'No' answer is sufficient. Column 5 shows the necessary relation between columns 3 and 4 in order to robotize. If the relation on column 5 holds, then a 'Yes' answer with the given 


\begin{tabular}{|c|c|c|c|c|c|c|c|c|c|c|c|}
\hline & 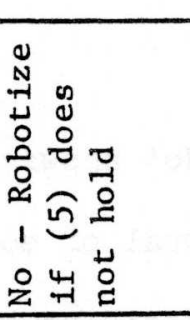 & 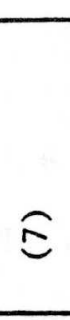 & 1 & & 1 & 1 & 1 & 1 & 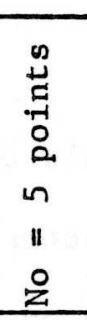 & 1 & 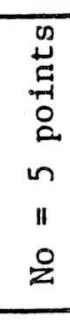 \\
\hline \multirow{6}{*}{ 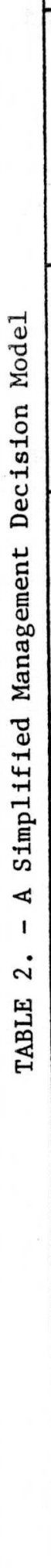 } & 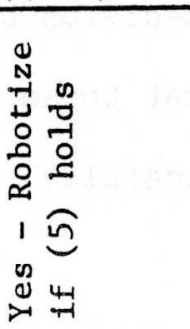 & $\hat{\theta}$ & 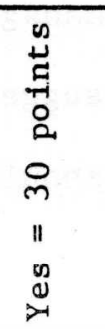 & & 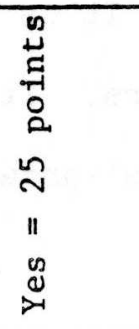 & 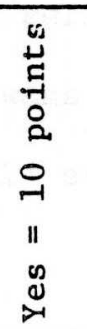 & 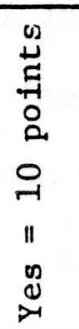 & 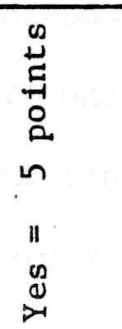 & 1 & 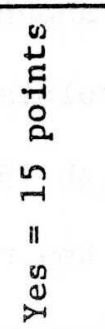 & 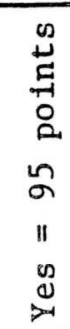 \\
\hline & 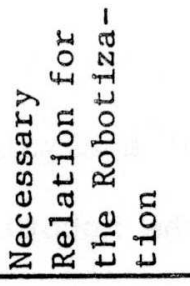 & ถ્ธ & $\hat{H^{-1}}$ & & $\hat{n}^{N}$ & $\begin{array}{l}m \\
v \\
m \\
m\end{array}$ & $\begin{array}{l}\mathrm{H}^{2} \\
\mathrm{H}^{2}\end{array}$ & $\begin{array}{l}n \\
-n \\
v \\
n\end{array}$ & $\begin{array}{l}-10 \\
v \\
H^{0}\end{array}$ & $\hat{r}$ & \\
\hline & 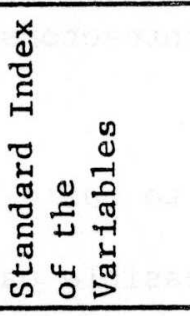 & $\widehat{\Xi}$ & $\begin{array}{l}n \\
\stackrel{0}{0} \\
0 \\
2 \\
n \\
\sim \\
\sim \\
11 \\
H^{-1}\end{array}$ & & 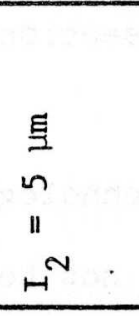 & 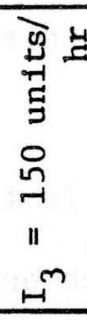 & 1 & 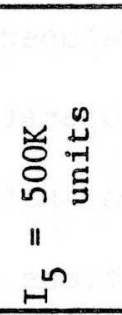 & 1 & 1 & \\
\hline & 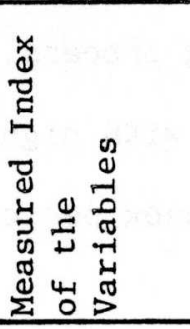 & $\widehat{\widehat{\sigma}}$ & 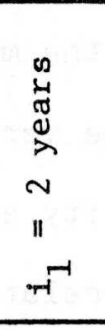 & & $\begin{array}{l}E \\
m \\
m \\
n\end{array}$ & 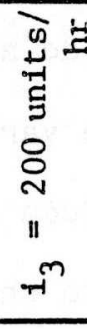 & 1 & 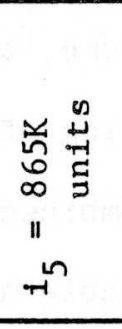 & 1 & 1 & \\
\hline & 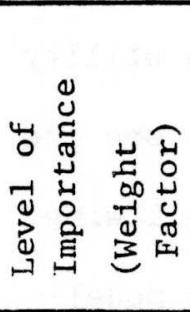 & $\widehat{\widehat{J}}$ & $\begin{array}{l}0 \\
\stackrel{5}{7} \\
\stackrel{7}{0} \\
\vdots \\
0 \\
0 \\
11 \\
11 \\
3^{-1}\end{array}$ & & 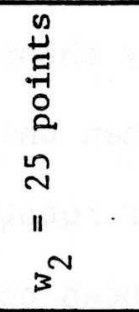 & $\begin{array}{c}20 \\
\stackrel{n}{n} \\
\vdots \\
0 \\
0 \\
0 \\
-1 \\
11 \\
3^{m}\end{array}$ & 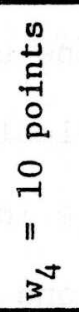 & 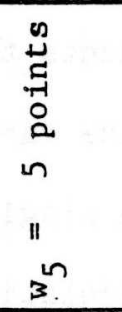 & 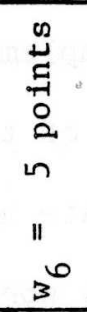 & $\begin{array}{c}n \\
\stackrel{n}{ \pm} \\
\stackrel{5}{0} \\
0 \\
\vdots \\
n \\
n \\
11 \\
11 \\
3\end{array}$ & 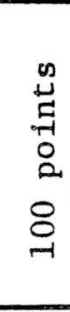 \\
\hline & 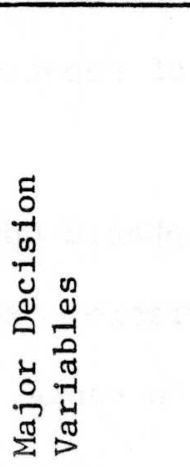 & $\widehat{త}$ & 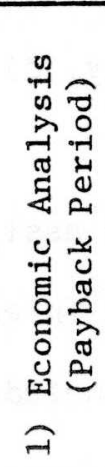 & 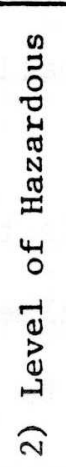 & 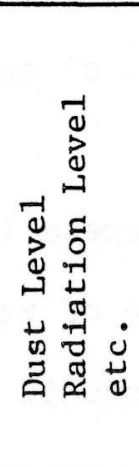 & 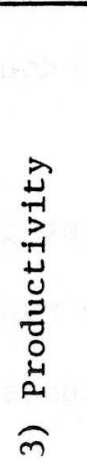 & 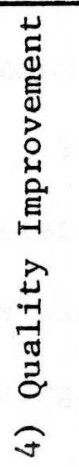 & 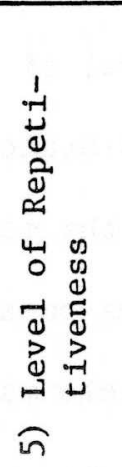 & 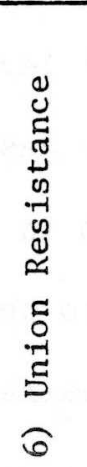 & 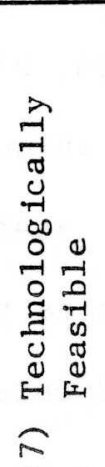 & 峞 \\
\hline
\end{tabular}


weight factor should be entered in column 6, otherwise, a 'No' answer with the same weight factor will be assigned to the column 7. Total of columns 6 , and 7 are shown on the last line. It is the management decision to find the cut-off points of the 'Yes' answers. It is suggested that those operations with 75 points or more 'Yes' answers should be carefully analyzed for the robotization.

\section{2) Detailed Feasibility Analysis by Utility Model:}

The management model described is a simple 'Yes' or 'No' analysis which can be used for the preliminary feasibility study of the robotization. A utility model is developed in this section to allow the contractors a detailed study of the operation.

This model assumes that it is technologically feasible to build a robot, and those operations which are not technologically feasible cannot be implemented, therefore, they do not apply to the modeling process. To avoid the double counting of the variables, those variables with high correlation will be combined. Such as productivity and payback period will be assumed as one variable due to their high correlation.

This model implements the utility theory to establish a utility function for each of the variables, then these utility functions are combined to estimate a single index of robotization. The following variables with low correlations have been considered in this model: a) payback period, b) level of hazardous, c) quality, d) level of repetitiveness, e) union resistance.

The next step in the modeling process is to assign acceptable upper and lower limits to the possible range of values in each variable. Both desirable and undesirable magnitudes should be included in the range. As 
shown in Fig. 7, these values are plotted along a horizontal axis, and the utility scale is the vertical axis. Two points on the utility scale are defined: 1.00 is assigned to the most preferred value, and zero is assigned to the point lying directly between the desirable values and undesirable values, a neutral point. A utility function can be developed between the two points on the scale.

As shown in Fig. 7a, a payback period of zero year is assumed to have the highest utility, and an accepted period of 2.5 years by the industry as the indifference point. In Fig. $7 \mathrm{~b}$, a dust particle size of $5 \mu \mathrm{m}$ is assumed as indifference point, in other words, if the level of dust particles are less than $5 \mu \mathrm{m}$, then the operation is suitable for the robotization, therefore, it has a positive utility (satisfaction). Fig. 7c shows two levels of quality $a_{1}$ and $a_{2}$ with zero and one utility value. These values must be estimated by the management. If the quality of the work performed by robot has a value less than $a_{1}$, then the implementation of robot based on this variable is not desirable. Fig. 7d is developed based on Fig. 6. If the level of repetitiveness is between $n_{3}$ and $n_{4}$, then the robots should be used. Level of $\mathrm{n}_{4}$ is an optimum repetition when the robotization is compared with the fixed automation. Fig. 7e divides the level of the union resistance into three levels: low, medium, and high. An average medium level is considered as zero utility. The assigned values should be adjusted by the decision maker under different conditions. To consider the impact of different variables and their individual contribution to the overall index, each of the measurement scales must be converted to one common scale. A set of scaling factors (weight factors) is used in the conversion. Each variable receives a scaling factor, the magnitude of which is based on the estimated importance of the variable to 


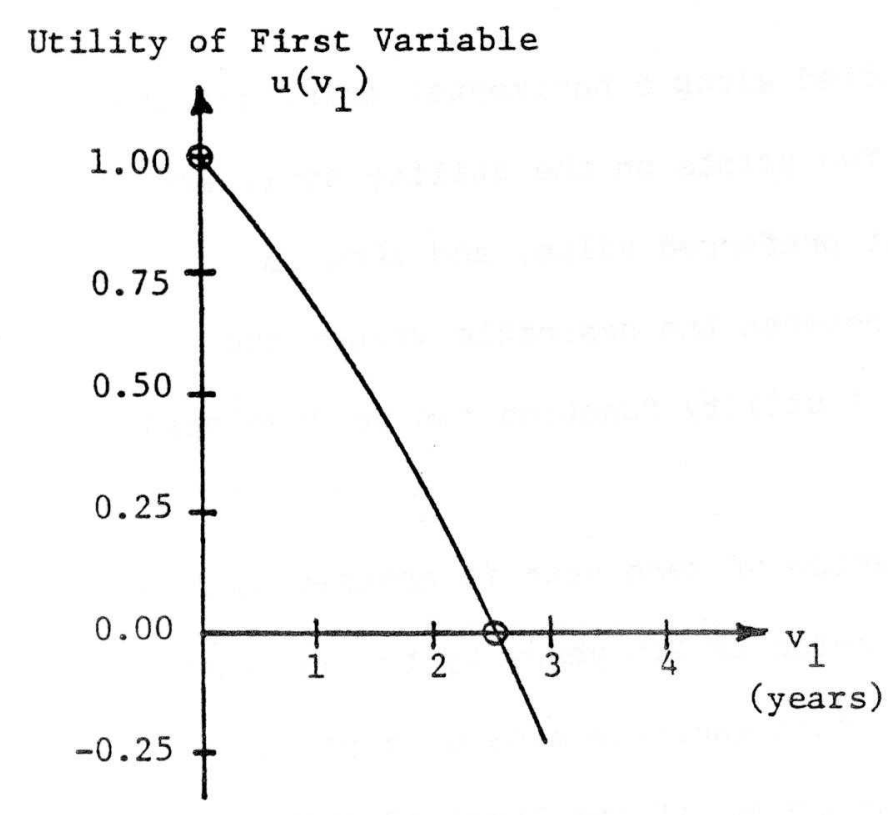

a) Payback Period vs. Utility

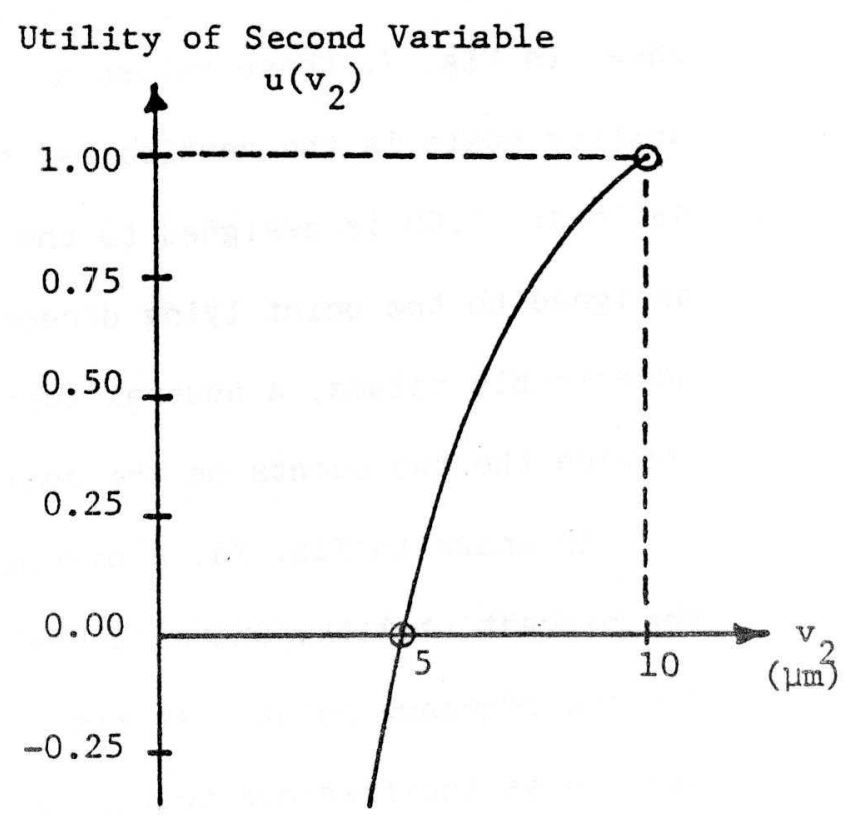

b) Size of Dust Particles vs. Utilit

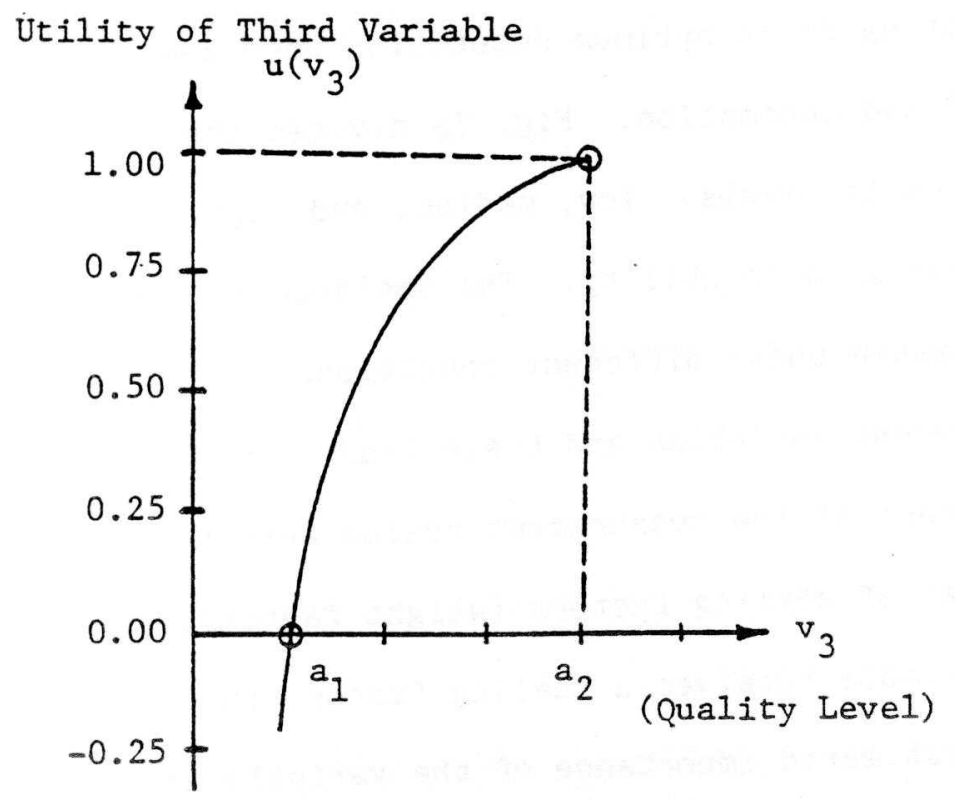

c) Quality vs. Utility

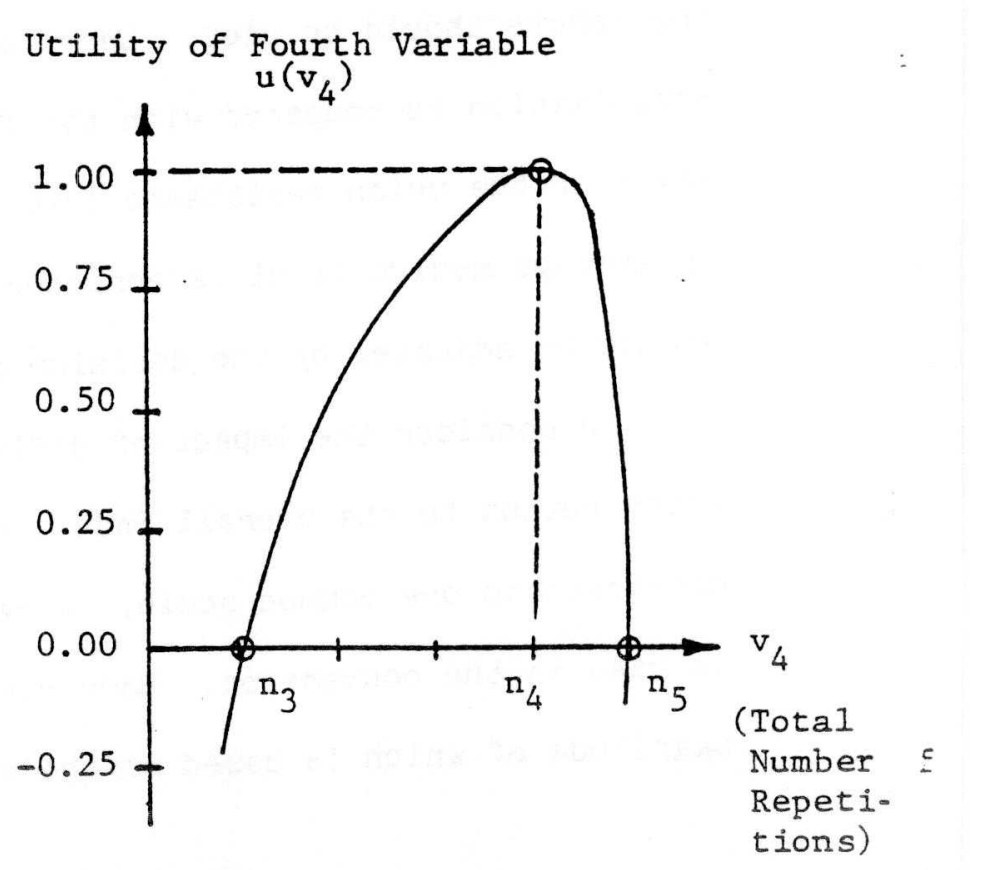

d) Level of Repetitiveness vs. Utili y 


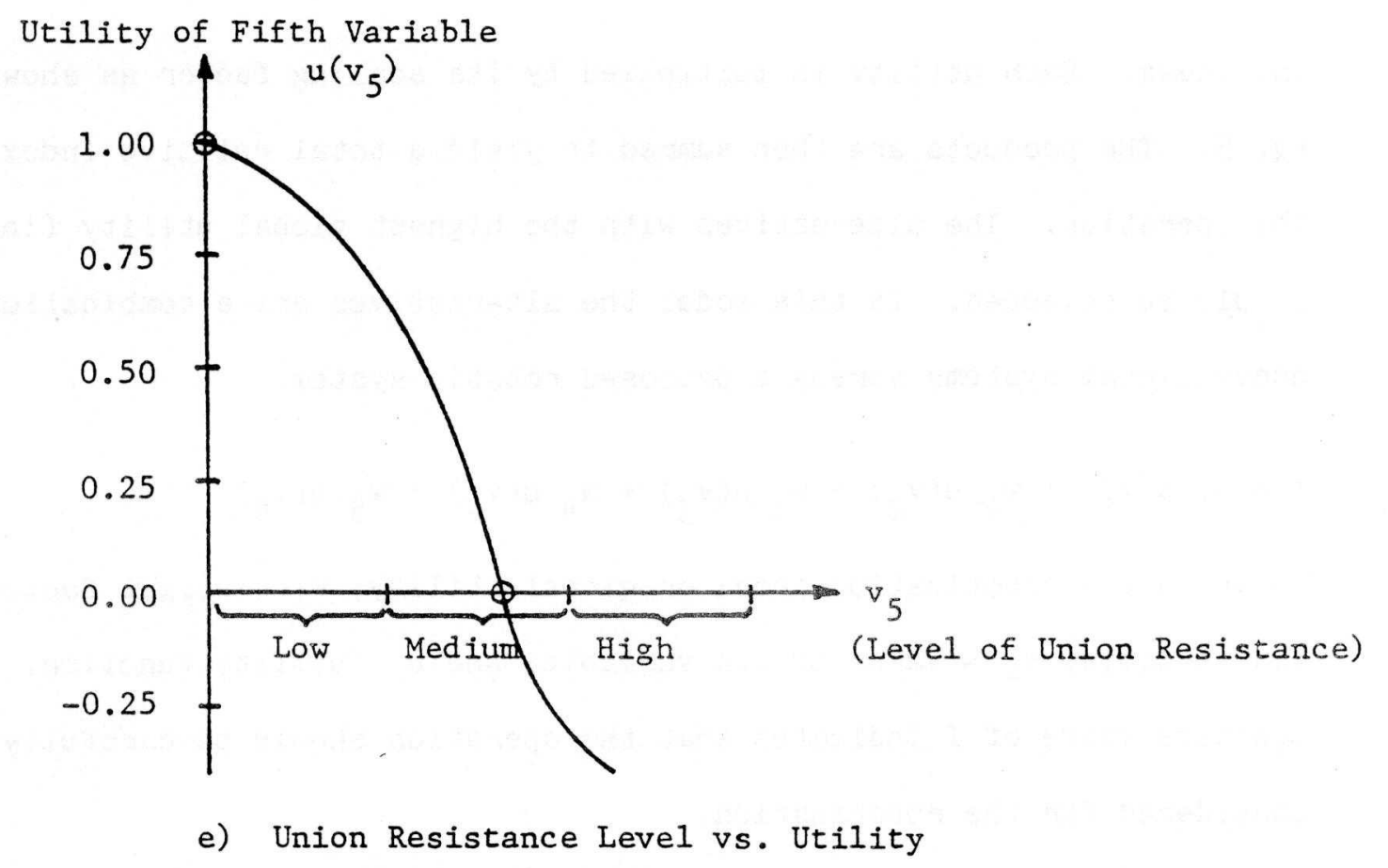

Fig. 7.- Utility Function of Each Variable 
the index. Each utility is multiplied by its scaling factor as shown in Eq. 5. The products are then summed to yield a total relative index for the operation. The alternatives with the highest global utility (index) should be selected. In this model the alternatives are a combination of conventional systems versus a proposed robotic system.

$I=w_{1} u\left(v_{1}\right)+w_{2} u\left(v_{2}\right)+w_{3} u\left(v_{3}\right)+w_{4} u\left(v_{4}\right)+w_{5} u\left(v_{5}\right)$

in which $I=$ robotization index or global utility; $w_{i}=$ weight factor of ith variable, $v_{i}=$ value of $i t h$ variable; and $u=$ utility function. $A$ positive value of I indicates that the operation should be carefully considered for the robotization.

The success of this model is directly related to the proper selection of the variables, accuracy of the utility curves and weight factors. If the decision criterion fall within separate disciplines of study then a professional in that area should be assigned to evaluate the measurement scale. In the assignment of weight factors the user must have a thorough knowledge of not only the operation tasks, but also the goals of the management. Overall the modeling of robotics for construction operations is necessary for the justification of implementation. The model enables the management to reduce the risks involved and consistently estimate the results of implementation. In the long run, this would aid in the increased use of robots throughout the industry. 
IV. SUMMARY AND CONCLUSIONS

Seven major variables affecting on the feasibility of the robotics in construction industry were identified as: 1) cost effectiveness; 2) level of hazardous; 3) productivity; 4) quality improvement; 5) standardization of design and level of repetitiveness; 6) union resistance; and 7) technologically feasible.

Two models were developed for the robotics feasibility in the construction industry: 1) simplified management decision model; and 2) utility decision model. The ultimate output of these models provide an index which indicates the level of automation.

Hazardous construction operations are the prime motivation in the U.S. to implement robotics in the construction domain. However, the problem of lower productivity in construction industry is expected to be an incentive for future use of robotics. Developing new design techniques based on standard elements and repetitive operations must be further investigated. This can result in developing entirely new techniques of construction, feasible for the robotization. 
V. ACKNOWLEDGEMENTS

The efforts of graduate students in the Construction Management Program at Georgia Institute of Technology are the basis of this report.

Appreciation is extended to H. Jones, S. Chawla, F。 Nakad, A. Gutierrez, P. Fernandez, and $C$. Obetts. 
VI. REFERENCES

1. Ayres, R.U., and Miller, S.M., "Robotics", Ballinger Publishing Co., Cambridge, Mass., 1983.

2. Berger, P., "Robot Catalog", Dodd, Mead and Co., New York, NY, 1984.

3. Carr, Robert I., "Simulation of Construction Project Duration", Journal of the Construction Division, ASCE, Vol. 105, No. C02, June 1979, pp. 117-128.

4. Carr, Robert I., and Meyer, Walter L., "Planning Construction of Repetitive Building Units", Journal of the Construction Division, Vol. 100, No. C03, September 1974.

5. Crawley, J.L., "Dynamic World Modeling and Navigation for an Intelligent Mobile Platform", Paper presented at the Workshop Conference on Robotics in Construction, Carnegie-Mellon University, Pittsburgh, PA, June 1984 .

6. Dabbas, Majed, A.A., and Daniel W. Halpin, "Integrated Project and Process Management", Journal of the Construction Division, ASCE, Vol. 108, No. C03, September 1982, pp. 361-374.

7. Engelberger, Joseph F., Robotics in Practice, Anacom, New York, 1980.

8. Fenves, S.J., and Rehak, D.R., "Role of Expert Systems in Construction Robotics", Paper presented at the Workshop Conference on Robotics in Construction, Carnegie-Mellon University, Pittsburgh, PA, June 1984.

9. Fondahl, J.W., "Photographic Analysis for Construction Operations", Journal of the Construction Division, ASCE, Vol. 86, No. C02, Proc. Paper 2483, May 1960, pp. 9-25.

10. Furukawa, Tsuned, "Introduction of Robots to the Construction Work Site", Robot, March 1983, pp. 14-19.

11. Halpin, Daniel W., "CYCLONE: Method for Modeling of Job Site Processes", Journal of the Construction Division, ASCE, Vol. 103, No. C03, Proc. Paper 13234, September 1977, pp. 489-499.

12. Halpin, D.W., and Woodhead, R.W., "Design of Construction and Process Operations", John Wiley and Sons, New York, NY, 1976.

13. Hasegawa, Yukio, "Robotization of Construction Work", Robot, March 1983 , pp. $41-46$.

14. Holland, J.M., "Basic Robotic Concepts", Howard W. Sams and Co., Inc., Indianapolis, IN, 1983.

15. Japan Mechatronics Letter, "Onbayashigumi to Develop Construction Robotics", May 20, 1983, p. 6. 
16. "Japan Takes Early Lead in Robotics", Engineering News Record, July $21,1983$.

17. Manninen, M., and Karkkainen, P., "Supervising Control of Large-Scaled Manipulators in Severe Environments", Paper presented at the Workshop Conference on Robotics in Construction, Carnegie-Mellon University, Pittsburgh, PA, June 1984.

18. "Mechatronics", Product News, Sedno 120A00, Komatsu America Corp., Norcross, GA, 1983.

19. Moore, W.C., "Application of Small Computers in Construction", ASCE Proceedings, ASCE National Convention, San Francisco, CA, October 1984.

20. Olishifski, J.B., "Fundamentals of Industrial Hygiene", 2nd Ed., National Safety Council, Chicago, IL, 1979.

21. Paulson, B.C., "Automated Control and Robotics for Heavy Construction," Paper presented at the Workshop Conference on Robotics in Construction, Carnegie-Mellon University, Pittsburgh, PA, June 1984.

22. Paulson, B.C., "Automated Control and Robotics for Construction", Paper presented to the Journal of Construction Engineering and Management, ASCE.

23. Rehak, D.R., and Fenves, S.J., "Expert Systems in Civil Engineering, Construction and Construction Robotics", 1984 Annual Research Review, Robotics Institute, Carnegie-Mellon University, Pittsburgh, PA.

24. "Robots: A Manager's Guide", Cincinnati Milacron, Cincinnati, $\mathrm{OH}$, 1982 .

25. "Robots Coming to Jobsites", Engineering News Record, February 10, 1983.

26. Safford, E.L., "Advanced Robotics", Tab Books Inc., Blue Ridge Summit, PA, 1982.

27. Sangrey, D.A., "Constraints on the Development of Robots for Construction", Civil Engineering Department, Carnegie-Mellon University, 1984 .

28. Shimomura, Y., and Sonoda, T., "Tunneling by Robots: Shield Driving Automatic Control System", Hazama-Gumi, Ltd., Paper presented at the Workshop Conference on Robotics in Construction, Carnegie-Mellon University, Pittsburgh, PA., June 1984.

29. Sullivan, B.J., "Industrialization in the Building Industry", Van Nostrand Reinhold Co., 1980.

30. Susnjara, K.J., "Industrial Robots", Prentice-Hall, Inc., Englewood Cliffs, NJ, 1982. 
31. Tamura, Y., and Kano, N., "A New Management Tool for Robotized Construction Projects", Paper presented at the Workshop Conference on Robotics in Construction, Carnegie-Mellon University, Pittsburgh, PA, June 1984.

32. Tarandi, V., and Birke, H., "A Pre-Study of Robotics in Construction", Paper presented at the Workshop Conference on Robotics in Construction, Carnegie-Mellon University, Pittsburgh, PA, June 1984.

33. Tucker, Richard L., et al., "Implementation of Foreman-Delay Surveys", Journal of the Construction Division, ASCE, Vol. 108, No. CO4, December, 1982, pp. 577-591.

34. Unchida, Seiichi, "Execution of Civil Engineering Work by Using Robots", Robot, March 1983, pp. 47-52.

35. Vallings, H.G., "Mechanism in Building", Second Edition, Applied Science Publishers, Ltd., 1975.

36. Vend, Takatoshi, "Robotization of Spraying Work for Fire Proofing Steel Structure", Robot, March 1983, pp. 53-61.

37. Warring, R.H., "Robots and Robotology", Tab Books Inc., Blue Ridge Summit, PA, 1983.

38. Warszawaki, A., "Application of Robotics to Building Construction", Paper presented at the Workshop Conference on Robotics in Construction, Carnegie-Mellon University, Pittsburgh, PA, June 1984.

39. Whittaker, W., "Remote Reconnaissance Vehicles", Technical Report, Carnegie-Melion University, The Robotics Institute, Pittsburgh, PA.

40. Yoshida, T., Veno, T., Nonaka, M., and Yamazaki, S., "Development of Spray Robot for Fireproof Cover Work", Paper presented at the Workshop Conference on Robotics in Construction, Carnegie-Mellon University, Pittsburgh, PA, June 1984.

41. Zeldman, M.I., "Robots", Marcel Dekker, Inc., New York, NY, 1984. 